\title{
General Psychiatry Prevalence of cognitive dysfunction, psychological morbidity and abuse in the community-based elderly population in India
}

\author{
Manjeet Singh Bhatia, Shruti Srivastava, Vishali Moond
}

To cite: Bhatia MS, Srivastava S, Moond V. Prevalence of cognitive dysfunction, psychological morbidity and abuse in the communitybased elderly population in India. General Psychiatry 2020;33:e100207. doi:10.1136/ gpsych-2020-100207

Received 11 February 2020 Revised 22 June 2020 Accepted 28 June 2020
Check for updates

(C) Author(s) (or their employer(s)) 2020. Re-use permitted under CC BY-NC. No commercial re-use. See rights and permissions. Published by BMJ.

Psychiatry, University College of Medical Sciences and Guru Tegh Bahadur Hospital, New Delhi, Delhi, India

Correspondence to Dr Manjeet Singh Bhatia; manbhatia1@rediffmail.com

\section{ABSTRACT}

Background The elderly population in India is expected to grow enormously by 2050 owing to an increase in life expectancy. Community-based data on the prevalence of psychological morbidity, abuse and cognitive dysfunction are scarce.

Aims To determine the prevalence of cognitive dysfunction, psychological morbidity and abuse in the elderly population in a resettlement colony from East Delhi, India.

Methods A cross-sectional study was conducted on the elderly population of a resettlement colony, in East Delhi, comprising 5 blocks and 12 subblocks with a total population of 65000 . The study was carried out within 2 months from April to August 2017. The self-reported questionnaires were administered to detect cognitive dysfunction, psychological morbidity, social support and pattern of abuse.

Results The mean age of the study subjects was 70.29 years $(53.8 \%$ were males, $78.8 \%$ were married, $86.9 \%$ were Hindus and $75 \%$ were living with children). A total of 106 subjects $(66.6 \%)$ belonged to the lower socioeconomic strata with $120(75 \%)$ living with children. Most of the subjects (70.6\%) studied below the primary level of education. As detected on Goldberg General Health Questionnaire-12, 56.9\% of the subjects had psychological morbidity. On Dementia Assessment by Rapid Test, 33.1\% of subjects were screened positive. The pattern of abuse reported was as follows: emotional abuse (16.9\%), physical abuse (7.5\%), sexual abuse (1.9\%) and social neglect $(18.1 \%)$. The social support score was found to be 46.22 (12.22)

Conclusion The results of this community-based study signify that appropriate steps at the policy level need to be undertaken so that abuse as well as neglect can be prevented. In addition, screening the elderly population helps to detect early cognitive dysfunction, psychological morbidity, abuse victims and individuals with poor support.

\section{INTRODUCTION}

Of 4.37 billion of the total world population, about 250 million are over the age of 65 years. ${ }^{1}$ The population of India increased from 685 million (geriatric group 6.4\%) in 1981 to 846 million (geriatric group $7.5 \%$ ) in 1991. The life expectancy of an average
Indian increased from 54 years in 1981 to 64.6 years in $2002 .{ }^{2}$ The elderly population rose from $6.0 \%$ to $8.0 \%$ during 1991 to 2011 due to factors such as better education and healthcare for the elderly according to a 2011 census in India. ${ }^{3}$ It is projected that the elderly population in India will rise to $12.4 \%$ by $2026 .{ }^{4}$

Cognitive function declines with advancing age particularly in older adults aged 60 years and above. Hence, concepts such as normal ageing, age-related cognitive decline, mild cognitive impairment (MCI)/dysfunction and cognitive disorders are used to denote the cognitive status of an older adult. There is evidence from the literature suggesting cognitive screening for the population above 60 years of age to detect MCI and dementia. A recent longitudinal Chinese follow-up study from 2005 to 2014 on 2603 participants conducted by Zhang et al using the Chinese version of Mini-Mental State Examination (MMSE) found deterioration of cognitive functions in $55.09 \%$ of the elderly. Different factors such as female gender, lower education level, increasing age, less income, no spouse, lack of social engagement, limited activities of daily living, lower intake of fresh fruits and vegetables were significantly associated with cognitive impairment. ${ }^{5}$ In India, routine cognitive screening of the elderly population is lacking, thereby leading to tremendous burden on the caregivers of elderly with dementia or MCI. Tripathi and Tiwari $^{6}$ conducted a study on cognitive screening to rule out impairment of different cognitive functions of older adults using mixed MMSE in which $14.42 \%$ of the elderly were positive (ie, scored 23 or below). A recent review by Porrselvi and Shankar stated that there is a lack of public awareness for cognitive testing in India. In addition, stigma, lack of infrastructure and trained manpower, 
lack of resources, multiple languages, cultural diversity, caregiving burden and lack of integrated services further makes it difficult for the public to understand the importance of routine cognitive testing. ${ }^{7}$ Cognitive impairment can be detected at an early stage if community-based screening is done.

Most of the elderly people with depression remain undiagnosed and untreated due to the lack of adequate knowledge of these disorders among the public and also because these symptoms are considered to be a part of normal ageing. ${ }^{8}$ Ritchie et at ${ }^{\dagger}$ found a lifetime prevalence of $26.5 \%$ and $30 \%$ of major depression and anxiety disorders, respectively, in geropsychiatric patients. In a study, Seby $e t a l^{10}$ found that $26.7 \%$ of the urban geriatric population suffers from psychiatric illness. Tiwari and Srivastava conducted a study among the rural population in India and found the prevalence of mental disorders to be high in the geriatric age group $(42.21 \%)$ when compared with the non-geriatric population $(3.97 \%)$, with depression and anxiety disorders being the most common disorders. ${ }^{1}$

Elder abuse is an undetected problem in many countries. Many forms of elder abuse exist including physical, psychological, financial, sexual and social neglect. Social neglect is experienced by the elderly through loss of friends and family members. A study by Saikia et $a l^{11}$ found the prevalence of abuse among community-dwelling elderly to be $9.31 \%$.

The elderly population is living mostly in impoverished conditions. Improved healthcare promises longevity but social and economic conditions such as poverty, break-up of joint families and poor services for the elderly pose a threat to their physical and psychological health. ${ }^{12}$ The lack of priority accorded to the healthcare needs of the elderly seems to perpetuate the low level of public awareness about the mental health problems of old age. The family is still the major provider of long-term care in the elderly, especially in developing countries like India, where institutional care is difficult to avail and is very costly. In a recent meta-analysis by Pilania et al carried out from 51 studies (1997-2016) involving 16 Indian states, the prevalence of depression was found to be $34.4 \%$ among elderly Indians. The rates of depression in the elderly was higher in females and in those from a rural background in this meta-analysis published in 2019. ${ }^{13}$

There is a need to study these aspects as most cases of elder abuse are under-reported and underdiagnosed. They reach to seek professional help at a much later stage. Hence, the early detection and screening of the elderly population for elder abuse will help to maintain a sound mental health without further progression of the morbidity. Owing to the paucity of available data, the current study was undertaken with the aim to determine the prevalence of cognitive dysfunction, psychological morbidity and abuse in the elderly population (60 years and above) in a community.

\section{METHODS}

\section{Study design, period and area}

A cross-sectional study was conducted in the elderly population of a resettlement colony, in East Delhi, with a total population of 65000 . The study was carried out from April to August 2017. A resettlement colony is defined as the transportation of people (as a family or colony) to a new settlement in the periphery of the city to decongest areas or to remove the encroachment of public places. Nand Nagari from East Delhi is a resettlement colony where the study was conducted. This area was chosen as the site for the study as it is at a convenient location from the institution and the entire mapping of this colony has already been done.

Two months were allotted exclusively for data collection from the community, and initial screening of the study population was carried out by the third author under the supervision of the first and second authors. Subsequently, the first and second authors evaluated the clinical diagnosis and confirmed the ratings and interpretation of the scales. In the remaining 3 months, data compilation, data entry, statistical analyses and writing of the results and discussion were completed. The report was submitted to the Indian Council of Medical Research in the stipulated time that gave the approval for this research report. Subsequently, the manuscript was prepared for publication.

\section{Inclusion criteria}

- Older adults (males and females) aged 60 years and above:

i. Confirmation of the age was done by using one or more of the following criteria:

a. An authentic document/certificate;

b. Retirement year (if retired);

c. Date of birth before the year of Indian independence (1947).

\section{- Cooperative persons.}

\section{Exclusion criteria}

- Having been diagnosed as suffering from any major psychiatric disorder as a main or comorbid condition other than MCI and dementia.

- Having any problem suggesting significant organic pathology, such as head injury, seizure, mental retardation, substance abuse, etc, or having physical health problems that affect an individual's daily functioning during the past 1 year.

- Having problems with speech, hearing and vision, which can impede the interview.

\section{Sample size determination and technique}

In this area of study, there were 5 blocks and each block had 12 subblocks, that is, a total of 60 subblocks. Each subblock was screened, and three subjects were randomly selected for the study. It was based on the maximum prevalence of psychological morbidity, cognitive dysfunction and elder abuse. ${ }^{11} 1415$ Using the prevalence of $43 \%$ for cognitive dysfunction, psychological morbidity 
and abuse, the relative marginal error is $25 \%$ on either side at alpha $=5 \%$, and a sample size of 85 subjects is required. To calculate the sample size, a formula, 4pq/ $\mathrm{dd}^{2}$ where $(\mathrm{p}=0.43 ; \mathrm{q}=0.57 ; \mathrm{d}=25 \%$ of $\mathrm{p})$, was used. Multiplying by a design effect factor of 1.5 (because of the block and subblock clustering effect), the sample got escalated to 128 subjects. Non-responders were expected to be $10 \%$. Therefore, the minimum sample of 141 cases was committed for the study. However, during the study period, we were able to include 185 cases due to the availability of time and resources, that is, 3 subjects per subblock.

\section{Data collection procedures and instruments}

A written informed consent from the study subject was obtained after explaining the intention of the study. Confidentiality of information was assured to the participants, and they were interviewed in the privacy of their home. The patient information was collected in privacy and noted in a semistructured data sheet specially designed for the purpose of the study. The interview was conducted by the trained investigator (author 3) under the supervision of senior psychiatrists (other authors). The collected information was validated by the supervisors (authors 1 and 2) using further elaborate interviews, history taking and detailed clinical assessments for cognitive dysfunction, psychological morbidity and abuse in the second stage interviews conducted in the hospital setting so that appropriate interventions could be provided to study subjects on priority. Sixteen study subjects were excluded from the study as shown in figure 1 . The selection of patients is given in figure 1.

The following measures were used:

1. The patient information was noted in a semistructured sociodemographic and history data sheet.

2. The Kuppuswamy Scale ${ }^{16}$ gives the socioeconomic status of the Indian population. This scale uses the following parameters, namely, family income, education and occupation. The sum of scores of these three parameters gives the level of socioeconomic status. Three levels of socioeconomic status with the following scores

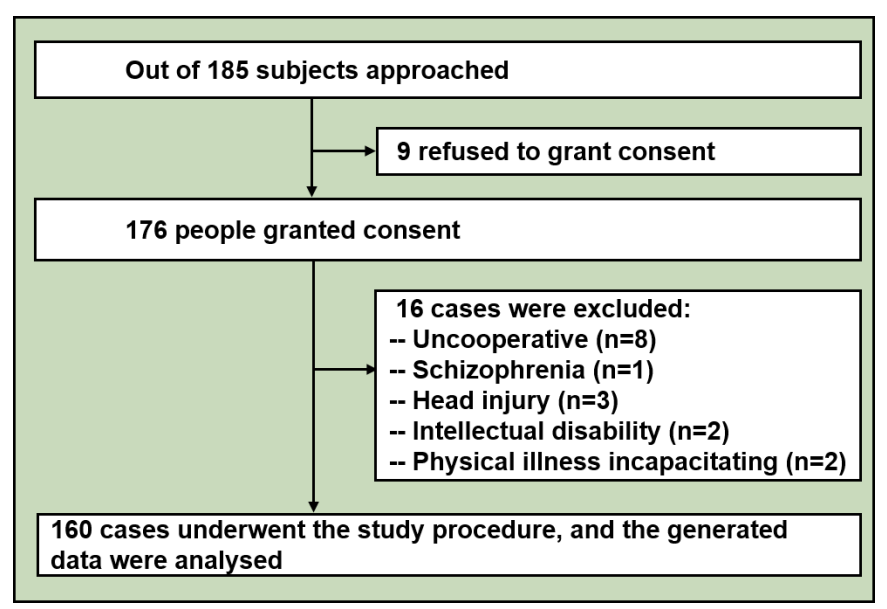

Figure 1 Schematic representation of selection of cases. were considered, namely, upper (26-29), middle (11-25) and lower $(<5-10)$ socioeconomic levels. A modified version of the Kuppuswamy Scale was used, in which the family income scale scores specifically for the Indian population were revised.

3. A Hindi version of MMSE (HMSE) was used ${ }^{17}$ that had 21 questions with a total score of 30. HMSE was developed in an Indo-US collaboration. The development of the Hindi version involved combining a group of American, rural elderly people with Hindi-speaking, rural Indian elderly people. The purpose was to develop a tool for conducting epidemiological studies of dementia for the rural elderly population that was largely illiterate and Hindi speaking. HMSE has modified questions on orientation to time and place, registration, attention (days of the week in backward order instead of 'WORLD', serial seven subtraction in the form of a problem), naming, repetition, reading (removed), carrying out commands, writing (removed) instead of saying a command allowed and copying a figure, so that all these modified items were culturally sensitive, locally acceptable and could be easily understood by the largely illiterate elderly population. HMSE scores of 23 or less were indicative of cognitive decline.

4. Dementia Assessment by Rapid Test $\left(\right.$ DART) ${ }^{18}$ is a quick screening tool for the assessment of dementia. DART has a sensitivity of $95.5 \%$ and specificity of $60.0 \%$ when compared with MMSE. It contains four questions that involve repeating dissimilar words, naming, recalling dissimilar words and clock drawing, with each item getting a score of 0 or 1 . Low scores indicate no impairment and higher scores reflect cognitive impairment. The range of scores is from 0 to 4 .

5. The Hindi version of the Goldberg General Health Questionnaire $(\mathrm{GHQ})^{19}$ was developed to detect psychiatric morbidity on comparing the normal population with psychiatric patients. The Hindi version of GHQ was found to be a reliable and valid tool as compared with the English version. Each item was scored on a Likert scale, 0-0-1-1, in the following order: better than usual, same as usual, worse than usual, much more worse than usual. A twelve-item version of GHQ is a reliable tool to study psychiatric morbidity in the elderly population..$^{20} \mathrm{~A}$ risk of developing psychiatric disorders was found with a score $>2$. There are questions related to overall happiness, disturbed sleep, depression and anxiety symptoms and stress in recent weeks or days. The scale has included clarifications, non-specific encouragement and cues so that the questions can be easily understood by the study sample. This tool was helpful in screening the community-based population. The psychiatric diagnosis was subsequently confirmed by the principal and second author.

6. The Hindi version of the Social Support Questionnaire (SSQ) is an adaptation of SSQ by Pollack and Harris with good internal consistency, reliability and validity. ${ }^{21}$ It consists of 18 questions, each question scoring from $0-1-2-3-4$, and the maximum score of the scale is 72 . 


\begin{tabular}{|c|c|}
\hline Sociodemographic variables & $\begin{array}{l}\text { Patients }(n=160) \\
\text { n (\%) }\end{array}$ \\
\hline \multicolumn{2}{|l|}{ Gender } \\
\hline Male & $86(53.8)$ \\
\hline Female & $74(46.3)$ \\
\hline \multicolumn{2}{|l|}{ Qualification } \\
\hline Professional/Honours & $2(1.3)$ \\
\hline Graduate/Postgraduate & $4(2.5)$ \\
\hline $\begin{array}{l}\text { Intermediate or posthigh school } \\
\text { diploma }\end{array}$ & $0(0)$ \\
\hline High school & $21(13.1)$ \\
\hline Middle school & $8(5)$ \\
\hline Primary school & $12(7.5)$ \\
\hline Illiterate & $113(70.6)$ \\
\hline \multicolumn{2}{|l|}{ Occupation } \\
\hline Semi-profession & $10(6.3)$ \\
\hline Clerical, shop-owner & $11(6.9)$ \\
\hline Skilled worker & $10(6.3)$ \\
\hline Semi-skilled worker & $18(11.2)$ \\
\hline Unskilled worker & 44 (27.5) \\
\hline Unemployed & $67(41.8)$ \\
\hline \multicolumn{2}{|l|}{ Income (rupees) } \\
\hline$>41430$ & $11(6.9)$ \\
\hline $20715-41429$ & $30(18.8)$ \\
\hline 15536-20 714 & $8(5.0)$ \\
\hline $10357-15535$ & $26(16.2)$ \\
\hline $6214-10356$ & $52(32.5)$ \\
\hline $2092-6213$ & $33(20.6)$ \\
\hline
\end{tabular}

"'n" indicates number, and figures in bracket are percentages

The higher the score, higher is the perceived support. The purpose of this scale is to quantify the availability and satisfaction with social support. Social support helps individuals to withstand the deleterious effects of stress.

7. The Patient Abuse Questionnaire (Hindi version) was developed by authors based on the WHO Domestic Violence Questionnaire. ${ }^{22}$ This tool was found to be useful in a previous study on psychiatric patients to assess emotional, physical and sexual abuse and neglect (medical negligence, negligence related to food intake, and economic deprivation). The scale had 11 items with yes or no responses for each of the items. The distribution of different items is as follows: emotional abuse 2 items (11 questions), physical abuse 1 item (6 questions), sexual abuse 2 items (3 questions and 1 question showing picture), 3 items confirming emotional, physical and sexual abuse, medical neglect 1 item, food negligence 1 item, economic deprivation 1 item.
Tools included $\mathrm{HMSE}^{14}$ containing 21 questions (total score of 30). Those with scores 23 or less were assessed further for cognitive decline. DART containing four questions with a score of $0-4$ was used to detect dementia. ${ }^{14}$ GHQ-12 (Hindi version, containing 12 items, each with a score of 0 or 1) was used to detect those likely to have or be at risk of developing psychiatric disorders (ie, score $>2){ }^{15}$ The psychiatric diagnosis was confirmed by the principal and second author. SSQ (in Hindi, having 18 items with a score of 1-4 and a maximum score of 72) was used to quantify availability and satisfaction with social support. ${ }^{16}$ To detect the pattern of abuse and neglect, the Hindi version of Patient Abuse Questionnaire (having 11 items with yes or no answers) was used. ${ }^{17}$

\section{Sampling technique and statistical analysis}

The collected data were edited, coded and entered into Epi-Data V.3.1 and then exported into Statistical Package for Social Sciences ${ }^{23}$ V.20 for analysis. Descriptive statistics was used. Mean (SD) was calculated and frequency distribution was given. Graphs were drawn in Microsoft Excel for a pictorial representation of the data.

\section{RESULTS}

\section{Sociodemographic characteristics}

Out of 185 elderly subjects who were approached, 9 (4.86\%) refused. One hundred seventy-six $(95.14 \%)$ responded to the study purpose. Another 16 cases were excluded due to other reasons as given in the flowchart in figure 1 . Out of the 160 patients studied, 74 (46.3\%) were females and $86(53.8 \%)$ were males. The mean age of the subjects was calculated to be 70.29 (8.87) years. A total of $126(78.8 \%)$ subjects were married and 34 (21.3\%) were either divorced or widowed; 139 (86.9\%) were Hindus, followed by Muslims (N-18; $11.3 \%)$ and Sikhs (N-3; 1.8\%); and $106(66.6 \%)$ belonged to lower socioeconomic strata with $120(75 \%)$ living with children while 40 (25\%) were living independently. Most of the subjects $(70.6 \%)$ had an education below the primary level. The sociodemographic profile of elderly subjects $(n=160)$ is shown in table 1.

\section{Clinical characteristics}

\section{Cognitive dysfunctions and psychological morbidity}

On HMSE, 50 subjects (31.3\%) were found to have cognitive dysfunction. A total of 53 subjects $(33.1 \%)$ were screened positive on DART for dementia. On GHQ-12, 91 subjects $(56.9 \%)$ were found to be having psychological morbidity (table 2).

HMSE was used to control the education and language bias. Those with scores $<23$ are supposed to have mild cognitive decline and should be assessed further. Fifty $(31.3 \%)$ of the elderly subjects had a score of 23 or below on HMSE. A total of $110(68.8 \%)$ elderly subjects had no cognitive impairment with an HMSE score $>23$. Age-wise cognitive impairment was calculated to be $30 \%$ in subjects 


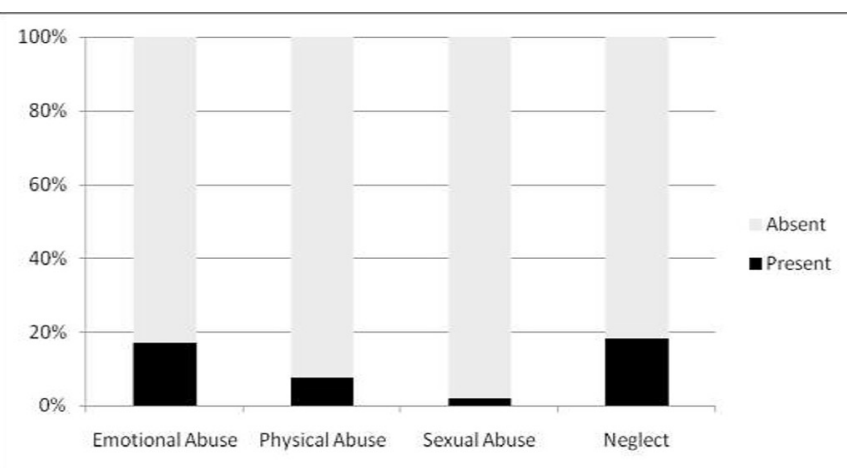

Figure 2 Distribution of different types of abuse and neglect in the study sample $(n=160)$.

aged 80 years or above out of a total of 50 cases showing cognitive impairment.

On evaluation, using DART, a score of 0 signifying no impairment was found in $107(66.9 \%)$ elderly subjects. Fifty-three $(33.1 \%)$ subjects were screened positive for cognitive impairment with a score ranging from 1 to 4 .

\section{Pattern of abuse}

Of 160 subjects, 27 subjects $(16.9 \%)$ had reported perceived psychological abuse in various forms such as invalidation of decisions, lack of privacy, troublesome, required to ask for permission, suicidal ideation, blamed and others made fun of their flaws. Twelve subjects $(7.5 \%)$ had reported physical abuse in all forms such as pushed forcefully, locked in a room and attempted to strangulate, use or warning to use weapons against them. Three subjects $(1.9 \%)$ had reported sexual abuse in terms of forced or unwilling sex by the partner or others. Out of 160 subjects, a total of 29 subjects $(18.1 \%)$ had reported neglect in various forms such as lack of financial support $(18.1 \%)$, food neglect $(10.6 \%)$ and medical neglect (16.3\%). Figure 2 shows the distribution of different types of abuse and neglect in the study sample $(n=160)$.

\section{Social support}

The mean social support score was 46.22 (12.227) with a maximum score of 61 and a minimum score of 25 in the elderly sample $(n=160)$.

Table 2 Cognitive dysfunction and psychological morbidity in the elderly sample $(n=160)$

\begin{tabular}{ccc}
\hline & Subjects & $\begin{array}{l}\text { Percentage } \\
(\%)\end{array}$ \\
\hline Cognitive dysfunction according to age (years) $(\mathrm{N}=50)$ \\
$60-69$ & 23 & 46 \\
$70-79$ & 12 & 24 \\
80 and above & 15 & 30 \\
\hline Psychological morbidity according to age (years) $(\mathrm{N}=91)$ \\
\hline $60-69$ & 39 & 42.8 \\
\hline $70-79$ & 24 & 26.4 \\
\hline 80 and above & 28 & 30.8 \\
\hline
\end{tabular}

\section{DISCUSSION}

\section{Main findings}

In a study by Tripathi and Tiwari ${ }^{6}$ on normally ageing of 104 urban older adults, 15 cases $(14.42 \%)$ were having cognitive dysfunction. In the present study, out of 160 subjects, 31.3\% had cognitive dysfunction; 23 (23.7\%) cases from 60 to 69 years of age, $12(37.5 \%)$ cases from 70 to 79 years of age and 15 (48.3\%) from 80 years of age were affected by cognitive dysfunction. Normally, ageing subjects had objective cognitive dysfunction in the areas of orientation and concentration and functioning or selfcare. It was found in elder adults with increasing age.

Similar findings were found using the DART scale, ${ }^{18}$ which has the potential to detect cognitive changes ranging from transitional changes from the preclinical stage to mild cognitive changes to dementia; $33.1 \%$ screened positive for dementia. The findings were similar on both the HMSE and DART scales. In a study on the elderly population by Gambhir et $a l^{15} 42.9 \%$ had scored below 23 on HMSE. The difference in the findings could be due to the better methodology of cognitive assessment using two screening tools as well as a detailed clinical examination providing higher sensitivity of detecting cognitive impairment. In a study carried out in Shanghai, an elderly sample $(n=480)$ over 80 years of age for a period of 2 months using MMSE reported cognitive impairment of $30 \%$, a finding similar to our study. ${ }^{24}$

In the present study, psychological morbidity was $42.8 \%$ in the age range of 60-69 years. In the same age range, Tiwari and Srivastava, ${ }^{1}$ Prasad $e t a l^{25}$ and Nandi et $a l^{26}$ reported morbidity of $59.7 \%, 74 \%$ and $87.6 \%$, respectively. In the present study, $26.3 \%$ of cases in the $70-79$ age group had psychological morbidity. Nandi et $a t^{26}$ and Tiwari and Srivastava ${ }^{1}$ reported $22.3 \%$ and $24.27 \%$, respectively, had psychological morbidity among patients in the same age group. In the 80 years and above category in our study, $30.7 \%$ of cases had psychological morbidity. Nandi et $a l^{26}$ and Tiwari and Srivastava ${ }^{1}$ reported a morbidity of $11.6 \%$ and $16.02 \%$, respectively. Reddy et $a l^{14}$ reported depression in $47 \%$ of the elderly population in rural areas of South India. A study by Xu et al on 3325 Chinese elderly people aged 60 years and above carried out in Tianjin city involved screening using a GHQ and a subsequent standardised assessment by a trained psychiatrist similar to our study. The one-month prevalence of mental disorders in that study was $14.27 \%$, and the lifetime prevalence of mental disorders was $24.20 \% .{ }^{27}$

In a study by Saikia et $a l,{ }^{11}$ aiming to find the prevalence and risk factors of abuse among the communitydwelling elderly people of Guwahati city, Assam, reported the prevalence of elder abuse to be $9.31 \%$. Neglect was the most common type of abuse reported. In a study by Kaur et $a l,{ }^{28}$ it was found that among the elderly residing in urban areas, social neglect was most common, followed by psychological abuse and financial abuse whereas among the elderly belonging to rural areas, physical abuse was more prevalent. In the present study, social neglect was present in $18.1 \%$ followed by 
emotional abuse $(16.9 \%)$ and physical abuse $(7.5 \%)$. Sexual abuse was found to be the least $(1.9 \%)$, probably due to the hesitancy to open up easily to an investigator. Overall, the results of abuse coincided with the previous studies, but the overall prevalence of abuse was found to be much higher $(18.1 \%)$ than reported $(9.1 \%)$ in the study by Saikia et $a l .{ }^{11}$ In a sample of 412 elderly subjects from mainland China, elder abuse and neglect was found in $35 \%$ of the participants. ${ }^{29}$

In a study on perceived social support and stigma in adults with diseased and normal control, Prakash et $a l^{30}$ found mean social support to be 46.23 (5.50). In the present study, the mean was found to be 46.22 (5.50). However, these mean figures on SSQ of the study sample were much lower than the maximum score of 72 that can be obtained using this scale, thereby reflecting poor social support in our study sample. The care of elderly people in India rests on the family members, who in turn experience caregiver burden associated with role overload. Role overload is defined as multiple social roles that the caregiver performs, often finding it difficult to manage time. Caregiver burden is reduced if the relationship quality of the elderly is better and they assist the caregiver in support tasks. ${ }^{31}$ In the present study, authors found that $75 \%$ of the elderly live with families. A recent meta-analysis on 24 observational studies carried out from Asia found good social support, living with the family, living with the spouse/ partner and having good social network were associated with less depressive symptoms. ${ }^{32}$

\section{Limitations}

The limitation of the study was that it was a crosssectional study having a small sample size, containing predominantly males. The results of the study cannot be generalised to the entire Indian population. No community-based intervention was used, and study subjects were shifted to an adjacent hospital setting. The positive aspects of the study were that it was a community-based study using standardised questionnaires and it had added knowledge on these important aspects.

\section{Implications}

It was found that cognitive dysfunction and psychological morbidity were more prevalent in the individuals with increasing age, and neglect was the most common form of abuse followed by emotional, physical and sexual abuse. This signifies that appropriate steps at the policy level need to be undertaken so that this menace is prevented and early intervention can be carried out. In addition, the screening of the elderly population helps to detect cognitive dysfunction $(33.1 \%)$ and psychological morbidity $(56.9 \%)$. Early timely intervention will help in improving quality of life in the elderly population. Future studies are needed to examine the impact of elder abuse on stress biomarkers associated with elder abuse. There is also the need to provide separate laws to deal with problems of elder abuse as had been in force for child abuse. ${ }^{24}$

Contributors MSB and SS conceptualised the research work and study design. VM collected the initial screening data under supervision of MSB and SS. MSB and SS carried out the evaluation, interpretation of the scales and findings. All the three authors were involved in analysing the results. MSB and SS interpreted the results. All authors approved the final manuscript.

Funding The study was conducted under Indian Council of Medical ResearchStudent Short Term Project (ICMR STS) (Reference no. 2017-07195).

Competing interests None declared.

Patient consent for publication Not required.

Ethics approval Institutional ethics committee approval was taken for carrying out the research work (number IEC-HR/2017/29/14).

Provenance and peer review Not commissioned; externally peer reviewed.

Data availability statement № data are available. Data collected are confidential and not in the public domain.

Open access This is an open access article distributed in accordance with the Creative Commons Attribution Non Commercial (CC BY-NC 4.0) license, which permits others to distribute, remix, adapt, build upon this work non-commercially, and license their derivative works on different terms, provided the original work is properly cited, appropriate credit is given, any changes made indicated, and the use is non-commercial. See: http://creativecommons.org/licenses/by-nc/4.0/.

\section{REFERENCES}

1 Tiwari SC, Srivastava S. Geropsychiatric morbidity in rural Uttar Pradesh. Indian J Psychiatry 1998;40:266-73.

2 Ministry of Health and Family Welfare, Government of India. Annual report: health plan and policy. New Delhi: Ministry of Health and Family Welfare, 2002: 15.

3 Population composition. Available: http://censusindia.gov.in/vital statistics/SRS_Report/9Chap\%202\%20-\%202011.pdf [Accessed 19 Apr 2020].

4 Situational Analysis of The elderly in India. Central Statistics Office. Ministry of Statistics \& Programme Implementation, Government of India, 2011. Available: mospi.nic.in/./publication_reports/elderly_in_ india.pdf [Accessed 19 Apr 2020].

5 Zhang Q, Wu Y, Han T, et al. Changes in cognitive function and risk factors for cognitive impairment of the elderly in China: 2005-2014. Int J Environ Res Public Health 2019;16:2847.

6 Tripathi RK, Tiwari SC. Cognitive dysfunction in normally aging urban older adults: a community-based study. Indian J Psychol Med 2011;33:177-81.

7 Porrselvi AP, Shankar V. Status of cognitive testing of adults in India. Ann Indian Acad Neurol 2017;20:334-40.

8 Singh AP, Kumar KL, Reddy CMPK. Psychiatric morbidity in geriatric population in old age homes and community: a comparative study. Indian J Psychol Med 2012;34:39-43.

9 Ritchie K, Artero S, Beluche I, et al. Prevalence of DSM-IV psychiatric disorder in the French elderly population. Br J Psychiatry 2004;184:147-52.

10 Seby K, Chaudhury S, Chakraborty R. Prevalence of psychiatric and physical morbidity in an urban geriatric population. Indian $\mathrm{J}$ Psychiatry 2011;53:121-7.

11 Saikia AM, Mahanta N, Mahanta A, et al. Prevalence and risk factors of abuse among community Dwelling elderly of Guwahati City, Assam. Indian J Community Med 2015;40:279-81.

12 Venkobarao A. Gero-psychiatry in Indian culture. Can J Psychiatry 1979;25:431-6.

13 Pilania M, Yadav V, Bairwa M, et al. Prevalence of depression among the elderly (60years and above) population in India, 19972016: a systematic review and meta-analysis. BMC Public Health 2019;19:832.

14 Reddy NB, Pallavi M, Reddy NN, et al. Psychological morbidity status among the rural geriatric population of Tamil Nadu, India: a cross-sectional study. Indian J Psychol Med 2012;34:227-31.

15 Gambhir IS, Khurana V, Kishore D, et al. A clinico-epidemiological study of cognitive function status of community-dwelling elderly. Indian J Psychiatry 2014;56:365-70.

16 Gururaj M. Kuppuswamy"s Socio-economic Status Scale- A Revision of Income Parameter for 2014. Int J Recent Trends Sci Tech $2014 ; 11: 1-2$. 
17 Ganguli M, Ratcliff G, Chandra V, et al. A Hindi version of the MMSE: the development of a cognitive screening instrument for a largely illiterate rural elderly population in India. Int $J$ Geriatr Psychiatry 1995;10:367-77.

18 Swati B S, Manjari T, Ashima N. Dementia Assessment by Rapid Test(DART): An Indian Screening Tool for Dementia, Journal of Alzheimer's Disease and Parkinsonism, 2015. Available: http://www. omicsonline.org/open-access/dementia-assessment-by-rapid-testdart-an-indian-screening-t-oolfor-dementia-2161-0460-1000198.pdf [Accessed 20 Apr 2020].

19 Gautam S, Nijhawan M, Kamal P. Standardisation of Hindi version of goldbergs general health questionnaire. Indian J Psychiatry 1987;29:63-6.

20 Qin M, Vlachantoni A, Evandrou M, et al. General health Questionnaire-12 reliability, factor structure, and external validity among older adults in India. Indian J Psychiatry 2018;60:56-9.

21 Nehra R, Kulhara P, Verma SK. Adaptation of social support questionnaire in Hindi: Indian setting. Indian J Clin Psychol 1996;23:33-9.

22 Bhatia MS, Srivastava S, Khyati M, et al. Prevalence of abuse in mentally ill patients visiting outpatient setting in a tertiary care hospital in India. Med Sci Law 2016;56:91-8.

23 IBM Corp. IBM SPSS statistics for windows, version 20.0. Armonk, NY: IBM Corp, 2011.
24 Ren L, Zheng Y, Wu L, et al. Investigation of the prevalence of cognitive impairment and its risk factors within the elderly population in Shanghai, China. Sci Rep 2018;8:3575.

25 Prasad KM, Sreenivas KN, Ashok MV, et al. Psychogeriatric patients - a sociodemographic and clinical profile. Indian J Psychiatry 1996;38:178-81.

26 Nandi PS, Banerjee G, Mukherjee SP, et al. A study of psychiatric morbidity of the elderly population of a rural community in West Bengal. Indian J Psychiatry 1997;39:122-9.

27 Xu G, Chen G, Zhou Q, et al. Prevalence of mental disorders among older Chinese people in Tianjin City. Can J Psychiatry 2017;62:778-86.

28 Kaur J, Kaur J, Sujata N. Comparative study on perceived abuse and social neglect among rural and urban geriatric population. Indian $J$ Psychiatry 2015;57:375-8.

29 Dong X, Simon MA, Odwazny R, et al. Depression and elder abuse and neglect among a community-dwelling Chinese elderly population. J Elder Abuse Negl 2008;20:25-41.

30 Prakash P, Kumar P, Sinha VK. Perceived social support and stigma in the adult with epilepsy and normal control. Delhi Psychiatry $J$ 2014;17:92-9.

31 Gupta R, Pillai VK, Levy EF. Relationship quality and elder caregiver burden in India. JSI 2012;21:39-62.

32 Tengku Mohd TAM, Yunus RM, Hairi F, et al. Social support and depression among community dwelling older adults in Asia: a systematic review. BMJ Open 2019;9:e026667.

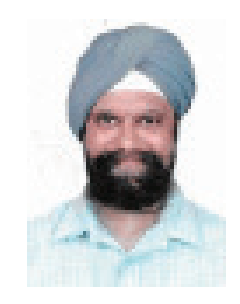

Professor Bhatia obtained a bachelor's degree of medicine in 1982 from Maulana Azad Medical College in Delhi University and an MD in psychiatry in 1987 from Lady Hardinge Medical University in Delhi University, New Delhi. He is currently a director professor and the head of the Department of Psychiatry, University College of Medical Sciences and Guru Teg Bahadur Hospital, Dilshad Garden, Delhi, India. He is also an editor of the Delhi Psychiatry Journal, field editor of the Indian Journal of Psychiatry, a member of the World Psychiatric Association, World Association of Social Psychiatry, and the World Federation for Biological Psychiatry. His main research interests include psychopharmacology, cultural psychiatry, consultation liaison psychiatry, and somatoform disorders. 